\title{
EVALUATION OF THE EFFECTS OF QUALITY MANAGEMENT SYSTEM IMPROVEMENT
}

\author{
Katarzyna SZCZEPAŃSKA*, Maciej URBANIAK** \\ *Faculty of Management \\ Warsaw University of Technology, Warsaw, Poland \\ e-mail: k.szczepanska@wz.pw.edu.pl \\ **Faculty of Management \\ University of Lodz, Lodz, Poland \\ e-mail: murb@uni.lodz.pl
}

\begin{abstract}
The article presents the tools that enable organizations to assess the effects of improvement of the quality management system, such as internal and external audits; risk management, measures of effectiveness and efficiency of processes, evaluation of customer satisfaction, quality cost analysis; analysis of best practices and self-assessment. The effectiveness use of these tools depends on the progress of the efforts of organizations in activities related to its improvement, knowledge and skills of employees and managers, who should show the positive attitude of leadership and involvement.
\end{abstract}

Key words: quality management, audits, effectiveness of processes best practice analysis, benchmarking, quality costs, self - assessment, quality awards.

\section{$1 \quad$ Introduction}

Assessing the effects of improvement of the quality management system enables an evaluation of processes and products by comparing them with the organization's objectives, standards (technical and organizational), as well as with other organizational units of both internal (its business units, such as departments, establishments, trading companies within the holding company) and external (competitors or entities that achieve the best results in each process activity areas). Assessment activities allow the organization to examine deviations from targets (including management standards), and thus identify areas for improvement and identify opportunities for improvement through the identification of needs for the introduction of organizational innovation and (or) product. Evaluation of the organization's activities aimed at improving the quality management system can be carried out through:

- audit of quality management system,

- risk analysis and measurement of risks,

- measures of effectiveness and efficiency of processes,

- evaluation of customer satisfaction,

- quality cost analysis,

- analysis of best practices (best practice analysis or benchmarking),

- self - assessment (e.g. according to the guidelines of ISO 9004, quality awards and models such as the Malcolm Baldrige Quality Award (MBQA),
Business Excellence Model (BEM, developed by EFQM- European Foundation for Quality Management).

Information obtained from these sources analyze the organization of periodic management reviews conducted by top management, which are used to assess the effectiveness of management systems.

\section{$2 \quad$ Audit of quality management system}

The effectiveness of the implementation, maintenance and improvement of quality management systems, occupational health and safety, information security, and sector - systems (i.e. HACCP, ISO /TS 16949), as well as other concepts to improve operational (such as the Toyota Production System, Lean Management or Six Sigma) is verified by independent study - audit. The audit of quality management system is to be understood as "the systematic and documented process for obtaining audit evidence and evaluating it objectively to determine the degree audit criteria" (ISO 19011:2003, p. 5). Audit records are evidence fact finding, or other information relevant to the audit criteria (for example, a set of policies, procedures, requirements) and other documents, which can be verified by an auditor during the audit. 
Audit quality management system can be:

- internal - carried out by the company called for management review, or to achieve other domestic purposes,

- external - conducted by the certification body called third party.

Conduct audits and assessments, as the tools used in quality management, are subject to compliance with key principles of auditing, which include (PN-EN ISO 19011:2009, pp. 7-8):

- independence - the basis of impartiality in carrying out the audit and objectivity in formulating conclusions from the audit,

- evidence-based approach - the use of a rational method for obtaining reliable and reproducible audit conclusions in a systematic his trial.

Audit is to collect evidence (by listening to questions, and observation of employee behavior, verification of documents and records), designed to determine the extent to which the organization meets certain criteria (customer needs and expectations of other stakeholders, the requirements of organizational and technical standards, legal rules and goals, or internal standards set by the organization.

Companies may conduct on their own assessment in relation to their processes realized by internal audits (audits of the first page) or can be done with potential and current suppliers. Sometimes also to customers (other audits), such as in the case of a franchise agreement for the production of goods or services (e.g. a network of sales, service repairs, hotels, petrol stations). A special type of audits are carried out by independent external organizations such as the unit management systems certification (third party audits.) These units must have appropriate accreditation entitling them to issue the certificates (the product's compliance with regulatory requirements - e.g. technical standards), or the compliance management system with the requirements of relevant standards such as ISO 9001, ISO 14001, PN-N 18001, OHSAS 18001, ISO 27001 .

The certification of quality management system may be also carried out on behalf of clients with independent audits of their suppliers. Both the audit of the first page, as well as third party (certification audit) in the assessment are taken into account the requirements of stand- ards, which are implemented based management systems by organizations, as well as company - specific regulatory requirements, customer requirements (other stakeholders), and set goals. In the case of audits on the other hand are the basis for assessing the requirements for suppliers (and as already mentioned in the dependency set customers, e.g. in the case of franchise agreement). The assessment shall be subject to audits: documentation (documents and records) relating to products and processes, implementation processes, available resources necessary to meet the requirements set (such as staff qualifications, quality of infrastructure and working environment to ensure security processes and products), as well as employee behavior observed during the execution of activities in processes, as well as their awareness of organizational goals and applicable standards of conduct.

Audit is an integral part of the program management process audits. It consists of four phases (see Fig. 1), in accordance with the principle of W.E. Deming the quality circles, in other words, the PDCA cycle (plan, do, check, act). Each of these steps, need to take certain actions, which completes the cycle of improvement of the audit program.

The scope of audit programs may vary depending on the size, nature and complexity of the organization. Regulatory requirements state that the factors influencing the scope of the audit are: purpose, duration, frequency of audit and the number, importance, complexity of the process of undergoing an audit.

Audit understood as to obtain an objective assessment appears to be sufficient to improve the quality management system according to ISO 9001:2009. The results of audits to be reviewed by the management company. Understanding the review can be static (compliance with standards) and dynamic (with the processes linking the environment). While the former are imposed, the latter are voluntary and represent a high knowledge of the managerial nature of quality management.

Treating the quality management system as an integral part of business management, you can ask questions about the effectiveness of this process. So far, it is assumed that the findings of the evaluation results are evidence gathered in relation to specific criteria, which may be procedures or requirements. 


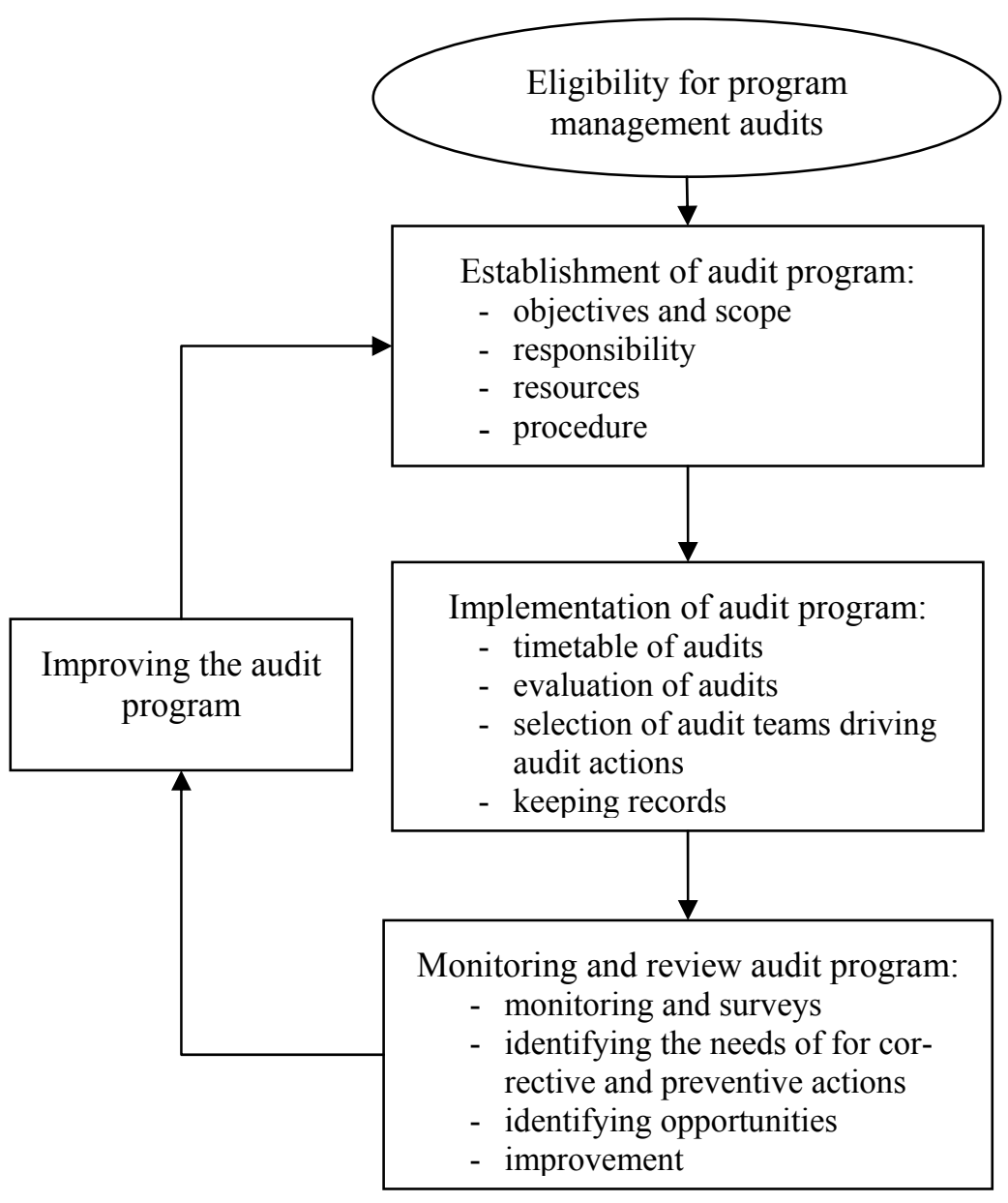

Figure 1. The process of audit program management (source: own work based on the PN-EN ISO 19011:2003:9)

In this sense, the scope of the audit is limited opportunity to evaluate the effectiveness of the management system. Therefore, it should be noted that if the quality management system is an integral part of enterprise management system, it seems to be insufficient classically understood role of the audit. Evaluations can be completed to determine if there are no developments in the quality management system, the company investigated, which significantly threaten the improvement of its activities. The answer to that question may provide a more informative value than finding the fulfilment of the criteria for audit. It can be assumed that the probable is a situation in which the audit criteria are fulfilled and yet further improvement of the business is threatened.

Another issue is to determine:

- degree (or level) of the threat, because it determines the pace and nature of managerial decisions,
- qualified person or persons to conduct such an evaluation.

Therefore, the scope of the audit may be extended by evaluate the system, within the meaning of management sciences. Without a doubt the finding of serious threats to the improvement of the business indicates the special responsibility of the auditor for the correctness of that assessment. This requires a greater range of expertise (management, finance, marketing, quality) and rich experience, which is currently neither a requirement nor a recommendation contained in the PN-EN ISO 19011:2003.

However, among the principles of auditing, special attention in the context of the presented considerations, in addition to ethical conduct, professional diligence, independence, deserve the following principles: the fair presentation (reflecting the state of affairs) and an approach based on evidence (the audit evidence should be verifiable). 
They are important because of the significant impact on the assessment of the effectiveness of quality management system and improve their diagnosis. Informing the customer (organization or person who receives the product) on the identified risks is intended to protect the interests of all beneficiaries of the enterprise, and thus is a prerequisite for security of the entire system of governance. If the structure of the audit objectives due to the needs of all stakeholders, it highlights another aspect of the expanded role and scope of audits carried out in the company. It is not merely about compliance of the quality management system requirements for regulatory or other action under the law, but also on its external and internal dimension in terms of governance, including in relation to the concept of value based management (VBM - Value Based Management), corporate social responsibility (CSR - Corporate Social Responsibility) and risk management. This represents a further justification for the claim that the auditing system should be oriented not only how to make standard on its effectiveness, but primarily on its effectiveness is related to the management system approach.

\section{$3 \quad$ Analysis and risk measurement}

Guidelines for auditing quality management systems, environmental management (PN-EN ISO19011: 2003) provide auditing principles, describe the actions and establish auditing and assessment of competence of auditors. However, there is no indication whether the analytical tools of vocations to the risk of loss of the ability of the system to improve it. Thus, it seems to be the development of risk assessment models, which reflect its nature, in terms of requirements of quality management system (PN-EN ISO 9001:2009). According to the concept of risk management, to measure the risk in situations of decision making on an ongoing basis to provide appropriate financial models and procedures for their application. The concept of risk model refers to the results achieved by the identification, evaluation and risk measurement.

The basis for the construction of such models is the classification of risks, using appropriate qualitative and quantitative methods. Risk management is generally understood as a process of methodical problem solving organization associated with the risk (for the treatment of risk) in such a way that these actions brought lasting benefits to all stakeholders. It is a system of continuous, planned and continuously refined covering both the organization's strategy and organizational procedures. This means that each identified risk in the form of business should be described in detail and continuously monitored based on specific indicators. Risk factors in terms of management can be divided into two main groups:

- external, which consists of risk: operational (legislation), financial (foreign exchange), strategic (fluctuation in demand, changes in subjective structure of the market) and risk (contracts, property),

- internal, which for example include: liquidity, cash flow, information systems and intellectual capital.

Scope and classification of risk factors are not, necessarily, the same for all companies. The variables include industry, company size, type and size of product groups, the scope and potential of markets (actual and potential). Examples of groups of risks can be:

- financial (loss of long - term contracts, cash - flow difficulties, excessive share of loans in the financing of long - term liabilities),

- operational (no license, the difficulty in obtaining raw materials, loss of productivity),

- organizational (conflicts with groups of staff, fast rotation at workplaces, lack of job descriptions, low level of ethics),

- competitive (inflation, changes in legislation, mergers and acquisitions, strategic alliances, technology transfer).

As is clear from the examples, it is possible to create a classification of risk groups and factors, the factors that may occur singly or in combination; a specific activity will be related to groups and risk factors. However, the importance of factors may be different depending on the industry and the environment in which the company operates. To determine the risk factors and how its measurement can be used recordings of ISO IEC TR 13335-3:1998, which relate to the following methods:

- A matrix of previously defined values - physical assets are valued at replacement cost, or play. Then the costs are converted to a qualitative scale, which are included levels of vulnerability and risk, and the resulting level of risk, rank the threats according to the degrees of risk - linking with each other consequences (the value of assets) and the likelihood of risks (including the vulnerable) 
and to determine the appropriate level of risk (in the order of priorities).

- Estimate the frequency and potential harm caused by risk - estimated value for each asset and the risk of the combination of which determines the result for each asset. When all the results of the assets for a given system is possible to define risk levels, which is exposed to this system.

- The difference between a roar as possible and unacceptable - risk measures are used only to his rank, thus indicating the place where the need for action is most urgent, and the same can be done with much less effort.

In addition, special attention should be paid danger of a qualitative nature. Financially irrational, in short periods of time, quality management, and developing relationships with clients intuitively to affect the assessment system's ability to improve, but there is no simple measurement apparatus. Market analysis provides the basis for determining the prospects for improvement, but without the continuous analysis of environment is substantially deficient.

Significantly, increase the probability of significant disturbance of the system is generally the result of the cumulative reduction in the pace of development of the system, but the negative phenomena in the surrounding businesses, the impact of which has not been adequately reflected in the award system.

The separation of the quality management system to market conditions, maladjustment causes expansion gaps (mismatches) of system solutions to the required level of quality management. In this sense, the quality management system can significantly limit the opportunities for flexible business operation.

Although essential to predict the difficulties to be encountered by auditors in evaluating the quality management system to improve mostly to be a situation in which there is no clear distinction between the situation in which the risk factor does not signal a threat and the situation still pointing to such a threat. This implies a need to assess the conditions of uncertainty associated with the lack of precise information.
Ambiguity is inherent feature of such notions as:

- appropriate level indicators,

- the level of risk corresponding to loss of ability to improve a specific configuration of risk factors,

- significant risks the development of improvement.

It is said that the essence of quality management system is improving in the sense that the system in the long term is to contribute to the development of relationships both externally and internally, but also to increase its efficiency, which in turn reduced to the concept of efficiency throughout the organization and specific benefits for beneficiaries (see Fig. 2).

You could say that the comparison of states: the benefits and requirements of all stakeholders is the basis for determining the real factors and measures for quality management. However, business is improving its platform.

Without a doubt, a statement of risks requires the application of additional procedures activities, which are based on action plans in the enterprise, designed with a view to prevent the loss of the system's ability to hone in on one side. On the other hand assessment of the feasibility of these plans and their impact on improving the situation of the company.

Thus increasing the responsibility of the auditor, as yet such plans are not part of system documentation. Non disclosure by the auditor of such hazards and their potential effects on the audit report, this is definitely proof that the principles of corporate social responsibility or are not established, or are not respected. Of course, we can assume the existence of cases in which the type and number of threats is high, and despite this degree of uncertainty as to the improvement of activity is low. In the case of monopolistic competition is acceptable. But we can also assume that this is not a common situation in the market, so this situation is a special case.

Recently, you may notice that more and more forms of acts associated with systemic risk management. These activities should be an ongoing process and developing process, which includes the organization's strategy and tools for its implementation. In this process should be postponed assumptions contained in its strategic goals into specific objectives at regular department's processes, and tasks for team or individual workers. Furthermore, the introduction of risk management involves the identification of operational procedures (taking into account the standard setting rules 


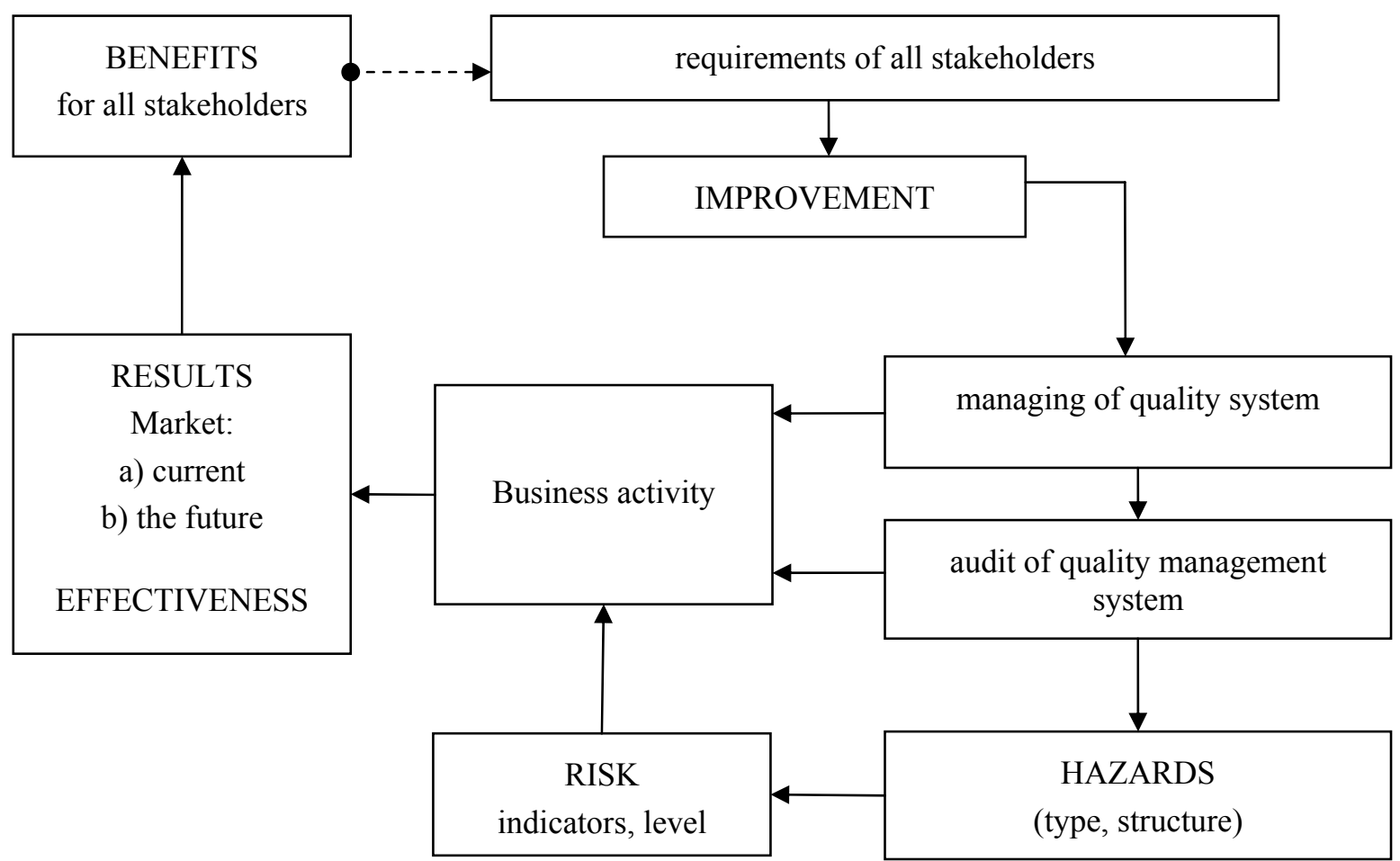

Figure 2. Risk as element of quality management system (source: own work)

of conduct, which can prevent incompatibilities and the procedure should they occur), accountability for results, monitoring and evaluation of achievements. Risk management, is based on the concept of continuous improvement and include the following steps (Urbaniak [12], pp. 157-170):

- term goals of the organization,

- identification of risks and their sources (causes),

- risk analysis (by mapping efforts to identify risk areas and sites of potential hazards, their description and measurement),

- assessment of risk (the probability of its occurrence and impact on the achievement of those objectives), the effectiveness of the means and methods of surveillance operations to control risks (the level) and reduce the effects of its influence,

- definition of objectives aimed at reducing risk and providing resources,

- define rules of conduct (procedures, contingency plans, record),

- information on the risk by raising the awareness of employees and other stakeholders,
- achievement of objectives through operational measures aimed at reducing the risk by taking corrective action, preventive and improvement measures to streamline procedures for risk management (focusing on reducing the level currently affecting the identification of new risks and threats and their sources).

These procedures relate to the methodology followed during the identification of risk, its analysis, the implementation of preventive and corrective actions taken to reduce (reduce) the impact of adverse events, monitoring the level of hazard, assess the effectiveness of safety management system. Improving quality management system through the use of risk management approaches companies use such guidelines contained in the example:

- Guide 73 - Risk Management. Vocabulary. Guidelines for use in standards, ISO IEC 2002,

- A risk management standard, IRM/ALARM/ AIRMIC, FARM, Brussels, 2002,

- AS/NZ 4360:2004 Australian/New Zealand Standard for Risk Management, 
- Risk Management: Guideline for Decision-MakersA National Standard for Canada, the Canadian Standard Association, 2002,

- The Orange Book, Management of Risk - Principles and Concepts, HM Treasury, London 2004,

- Enterprise Risk Management - Integrated Framework, COSO II, 2004,

- The EFQM. Framework for Risk Management. Driving Excellence in Risk Management, DNVEFQM, Brussels 2005,

- TR 19:2005: Technical Reference for business continuity management,

- BS 25999 - 1:2006 Code of practice for business continuity management,

- BS 25999-2:2007 Business continuity management,

- ISO 28000:2007 - Specification for security management systems for the supply chain,

- Management of Risk: Guidance for practitioner, the Office of Government Commerce, The Stationery Office, London, 2007,

- ISO/PAS 22399:2007, societal security - Guidelines for incident preparedness and operational continuity management,

- CSA Z1600 Standard on emergency management and continuity programs (draft standard for the Canadian Standards Association),

- ISO 31000:2009 Risk Management. Principles and Guidelines on Implementation.

One of the most commonly used tools that can identify threats in an enterprise risk processes and products (as well as to determine the possibility of their detection and potential impact and importance to the company and customer) and the design methodology of preventive and corrective actions are FMEA (Failure Mode and Effect Analysis). The identification of risk, you can also use relatively simple techniques such as flow diagrams (called flowcharts), lists - check cards (check sheets), mapping of processes (called process mapping), cause - effect diagrams (called cause and effect diagrams) or slightly more advanced as technology based decision tree based on whether the study of hazards and operational capability (Hazard and Operability Study, HAZOP).

Implementing the concept of risk management companies devote special attention to the operational tasks associated with processing customer orders (order han- dling, purchasing, design, manufacture the product or service, delivery and service activities) and assisting (supervision of infrastructure, financial management, human resources, and environment work). Their effective implementation determines the continuity of the organization. You can also see that more and more some of these processes are performed by external entities. The effect is that the companies buying these services work out a methodology for the qualification and periodic evaluation of suppliers, is also expecting their suppliers to implement risk management approaches.

The effects of the implementation of risk management approaches undoubtedly depend on the effectiveness of communication processes with stakeholder's organizations (especially the owners, customers, suppliers, employees). Of particular importance is creating awareness of the risks of the owners and their sympathy for the decisions taken by the management of business units focused on making investments in order to prevent threats. Building partnerships with customers and suppliers allows for time-synchronized and standardized processes of planning, ordering, designing, manufacturing, quality control and supply of products, and thus the formation of non-compliance products and organization. Raising employee awareness of the risk requires the implementation of periodic training and exercises to allow for an effective implementation of procedures related to their hazard identification, response to emergency situations and effectively eliminating their effects.

\section{Operational improvement measure indicators (assessment and process efficiency)}

Improving the business is possible only if it rests its decision on an analysis of operational activities. Such analysis is carried out, mostly with the use of metrics, so you can monitor both the current state of the implementation process and evaluate the results (achieved ratios) with the planned objectives (target indicators). With this analysis can provide direction for further action for the entire company and its units. Meters operating activities, can be divided into the following generic groups:

- financial, for example, variable costs, fixed costs, profitability, capacity, profit, 
- time, such as the length of the production cycle, product delivery, the time for a new product,

- quantitative and qualitative, such as the level of deficiencies, the number of complaints, production capacity, efficiency, productivity,

- flexibility and innovation, such as adjusting to changes in the environment and to demand, improving the skills of workers, flexible equipment in the means of production,

- social, such as division of labour (fair), ergonomic shape of the job, sense of job security,

- organic, such as the environmental burden of harmful emissions, consumption of natural resources.

To assess the operational processes and identify areas that need improvement, you can use the capacity or efficiency measures (Witt [14], p. 251). Capacity means the maximum quantity that can be produced in a specified time, utilization, specifying the amount of available capacity - e.g. manufacturing, warehousing, which is actually used (usually expressed as a percentage it is). Efficiency expresses the ratio of the current level (e.g. production) to the size of the achievable.

\section{$5 \quad$ Measuring customer satisfaction}

The requirements of quality management standards require the measurement of the degree of improvement of the organization by carrying out assessment of customer satisfaction. For this purpose, both methods of qualitative and quantitative.

The first flu can include the method of the questionnaire (using a questionnaire sent by mail, fax, e-mail), telephone interviews, personal interviews, as well as formal and informal opinions expressed.

The second group, should be classified as quantitative measures of such increase in sales value (in a given period), the percentage of re-purchase, the share of regular customers (loyalty indicator), the duration of business contacts, share further recommendations, the number of repeat purchases, the number and value of claims, shares market, loss of customer (the outflow rate of customers), the new clients.

The most common measure used by firms is the number and value of the claim. It must be regarded, as targeting the expression of dissatisfaction concerning the organization of (and often items of maintenance, or supply, such as timeliness, documentation, terms of pricing, service), or the process for dealing with complaints, which is expected or required response occurred explanatory problem and or proposed solution is its the process for dealing with complaints is a particularly sensitive and requires very precise definition of rules for communication with clients (Vos and Huitema [13], pp. 8-17).

In dealing with requirements of International Standards Organization has identified guidelines contained in ISO 10002:2004 (Quality management - Customer satisfaction-Guidelines for complaints handling in Organizations). Standard provides guidelines for designing and implementing an effective process for dealing with complaints for all types of transactions, including e-commerce. The information obtained in the process of dealing with complaints can be a source of improvements to the products and improve the image of the organization in the eyes of its customers (Hughes and Karapetrovic [4], pp. 1158-1175).

\section{Evaluation of the organization's activities through the analysis of quality costs}

The first studies on issues related to the cost of quality arose in the thirties and fifties of last century. Forerunners in this respect were, inter alia, Shewhart [7], Juran and Gryna [6] and Feigenbaum [2]. In the literature, there is no conclusive approach to the division of quality costs. Quality cost analysis can be conducted in a variety of approaches such as Stimson and Dlugopolski ([9], pp. 26-31); Sower, Quarles and Broussard ([8], pp. 121-140):

- analysis of the costs of prevention, assessment and gaps (PAF - prevention, appraisal and failure cost model),

- analysis of the costs of compliance and non - compliance (model PCM - Process Cost Model),

- analysis of the costs of internal and internal,

- analysis of costs by the life cycle.

The purpose of the cost of quality by Juran J.M. is (Szczepańska [10], p. 262]):

- identify all the types of actions and activities which lead to the achievement of the required product quality, regardless of their organizational division within the organization,

- determine the cost of operations and activities,

- interpreting information received makes it available to all concerned, 
Table 3. Optimum cost of quality

(source: Szczepańska [10], p. 265)

\begin{tabular}{|lr|ll|ll|}
\hline \multicolumn{2}{|c|}{ Zone projects to improve } & \multicolumn{2}{|c|}{ Neutral zone } & \multicolumn{2}{c|}{ Excellence zone } \\
\hline cost of defectiveness & $>70 \%$ & cost of defectiveness & $\sim 50 \%$ & cost of defectiveness & $<40 \%$ \\
assessment costs & $\sim 20 \%$ & assessment costs & $\sim 40 \%$ & assessment costs & $\sim 50 \%$ \\
prevention costs & $<10 \%$ & prevention costs & $\sim 10 \%$ & prevention costs & $>10 \%$ \\
\hline deficient & $100 \%$ & quality & $100 \%$ & good & $100 \%$ \\
\hline
\end{tabular}

- seek opportunities for cost optimization of production quality,

- organizing the current trends, observation and recording quality for the cost of a product or service.

Based on studies conducted in recent years by the Feigenbaum AV. costs of non-compliance can be estimated at $23 \%$ of sales, of which approximately $50 \%$ are costs of internal errors, $25 \%$ of the costs of external errors, about $20 \%$ of the costs of evaluation, and the remainder (approximately 5\%), baskets of prevention (Feigenbaum [2], pp. 22-27). Analysis of quality costs should allow the definition of zones of quality costs, which include: neutral, excellence and improvement projects (see Table 3). The share of costs in the total cost of sub - quality sets the zone to which you can qualify for the cost of the quality of a company, namely:

- Costs in the zone projects to improve - the production costs of defective exceed $70 \%$ of the total cost of quality, and prevention costs represent about $10 \%$ of the cost, with $20 \%$ share of the cost evaluation. With this level of costs, the company should establish a program to improve (lower level) the cost of quality.

- Costs in the neutral zone of the production defective is about $50 \%$ of the total quality costs, prevention costs represent about $10 \%$ of the costs, the assessment costs fluctuate around $40 \%$ share of the cost. So a certain level of costs is considered to be quality, and the efforts of companies should be focused on quality control techniques.

- In the area of excellence, cost of production of defective not exceed $40 \%$ of the total cost of quality and costs of preventing an approximately
$10 \%$ of the cost, with a $50 \%$ share of the cost of evaluating the cost structure. Companies with this level of costs should optimize quality costs by continuing to look for opportunities for reductions (audits, audit), the word continued process of continuous quality improvement.

Analyzing the relationship between the types of quality costs is also a pattern that the cost of reducing the level of non - compliance requires enterprises to bear the expenses for activities related to the control and prevention. The effectiveness of these measures should lead to lowering the total cost of quality.

\section{$7 \quad$ Benchmarking practices best analysis}

One of the conditions for continuous improvement of quality management systems is to analyze best practices often equated with a comparative evaluation or benchmarking. According to the definition proposed by the American Productivity and Quality Center. Benchmarking is a continuous and systematic performance measurement and comparisons of organizational processes in relation to the leaders in order to obtain information which will enable the organization to take certain actions involving the adaptation of best practices to increase their competitiveness.

Benchmarking is mostly define as a continuous systematic process, which consists in confronting their own effectiveness as measured productivity, quality and experience with the results of these companies and organizations that may be regarded as a model of excellence.

Most comparative evaluation starts from a comparison with the procedures of the process of global leaders and organizations identify strengths and opportunities 
for improving it. In addition to analyzing the products, processes and performance, this evaluation helps determine the causes of gaps that exist between products, processes, and performance of the company and used by world leaders.

Conducting comparative assessments allows businesses to identify practices used by other organizations (through the use of specific techniques for collecting information), get to know them and (in many cases) to adopt to improve their operations and improve (or fix) for it its competitive position (Haverty and Gorton [3], pp. 1077-1091). As for the best, the source may be an effective tool in the process of streamlining the processes indicated in conversations with customers and process mapping.

Benchmarking based on surveys that may be undertaken through telephone interviews during the conference, or by using the techniques of video inter-views conducted by correspondence for via mail and fax calls and during mutual visits, which make it possible to talk "face to face", and hands-on atmosphere and conditions of work in an environment benchmarking partner. Apart from the above research techniques in order to conduct comparative assessments are also used focus group interviews and other sources of information (e.g. reports, notes and newspaper articles). The process of benchmarking can be carried out within their own organizations, between subsidiaries of the group, within the holding companies, departments and functional areas of business. In many companies (especially international corporations), the comparison with the best starts of the internal benchmarking between business units.

A second option is to compare the analysis of competition in the sector. The subject of comparisons are carried out not only the quality parameters of products but also the efficiency and effectiveness of management processes, as well as perceived by customers criteria for the competitiveness of firms and their suppliers (compliance with the specifications of the offered quality - defective supply, product innovation, competitive pricing, timely delivery of orders, after - sales service, speed of response to inquiries and complaints, the powers of the sales and service personnel, compliance of documents with the delivery, performance management system and quality control, production capacity, offered terms of financing transactions, qualified managers) (Jang [5], pp. 919-930).

A third variant of the benchmarking study is to compare in terms of functional organization of the compa- ny, used management methods, strategies and specific activities such as focused on building quality systems, continuous improvement and learning benchmarking between companies from different sectors. Benchmarking not only apply the big giants, but also a method that is starting to spread in medium and small enterprises. Reference points in the comparative analysis may be: the technical quality of products (in relation to the technical parameters, modern solutions, the implementation rate of innovation), logistic processes (mostly on time delivery and flexibility), service activities, modern technological processes, the effectiveness of communication with customers, of the business to the environment (e.g. environmental protection, sponsorship, investing and creating new jobs), the perception of activities and communication companies (with particular emphasis on advertising, public relations), reference the company's competitiveness to stimulate buying behavior of buyers (to identify the major strengths affecting selection of the company as a supplier (e.g. elasticity, individualization of solutions, awareness and brand image), evaluation of personnel responsible for customer contact (professionalism, culture of service, completeness of the information, the speed in response to customers).

\section{Methods of self - assessment and quality awards}

The degree of improvement of the quality management system can be subjected to self or verified by seeking organizations to grant awards of quality. These awards are both at the international level (e.g. the European Quality Award, Prize Deming), national (e.g. the name of Malcolm Baldrige Award, Japan Quality Award, Polish Quality Award), regional and corporate (e.g. Philips Business Excellence, Tata Business Excellence Arumugam ([1], pp. 46-58). Overview of the winners and finalists of quality awards, points out that:

- in the European Quality Prize awarded in the years 1992-2008, was dominated by companies from Britain, Spain and Germany. Another country is Turkey, which has eight companies laureates,

- in the W. E. Deming Prize granted in the years 1951-2008, was dominated by Japanese industrial companies, however the largest number of winners of the companies concerned: Nippon, Toyota and Aisin, 
- M. Baldrige Prize awarded in the years 1988-2008, was dominated, in addition to industrial enterprises, companies representing the service sector (15), health care (8) and education (7),

- in the Polish Quality Prize, awarded for the years 1995-2008, was dominated by industrial companies, service (28) and public (25).

Criteria used in evaluating applicants for these awards are also for many organizations guidelines for improvement (e.g. they are self - assessment). These are complex models (also known as models of excellence, called excellence models), covering a wide spectrum of areas including but not limited with strategic planning, leadership, knowledge management, process management, customer relationship management and suppliers. It allows companies to identify opportunities for improvement in planning their development, resource development, implementation and performance.

Developing self-assessment, in the practical activities of the organization, bringing a number of tangible benefits, which are (Szczepańska [11], p. 343):

- disciplined and structured approach to improvement activities,

- an assessment based on facts and not on individual perceptions,

- consistency of directions in determining what should be implemented,

- integrating the various initiatives pro - quality with operations and processes,

- effective diagnosis,

- objective assessment in relation to a set of criteria,

- stimulant for the improvement of the management, focusing on areas where these improvements are the highest priority,

- methodology for use in all areas of management from a particular organizational unit until the entire organization.

Collecting and analyzing data by companies when carrying out self - assessment is increasingly using modern information technologies to enable effective use of them to make decisions related to the improvement of the operational organization. Applicants for the award, individuals must also be characterized by making efforts in the development of human resources by raising their level of competence and motivation of workers (allowing them to effectively solve prob- lems and implement corrective and preventive action, as well as a source of product innovation and organizational).

\section{Summary}

As can be seen from the foregoing considerations, the ways and methods for evaluating the effects of improvement of the quality management system should be included in a coherent system of measurement. Otherwise, evaluates the effects are only some improvement. It does not give a full picture of developments in the management of the company quality system. However, a comprehensive evaluation of the effects of improvement requires adequate data to conduct it. Without a doubt, it is also timeconsuming. As shown by practical examples, mostly in enterprises is used in the evaluation of audit and evaluation by customers. This demonstrates the limited approach of companies to improve the comprehensive assessment of the quality management system.

\section{Reference}

[1] Arumugam V. - Self - assessment of TQM practices: a case analysis [in] The TQM Journal, Vol. 21, No. 1, 2009, pp. 46-58.

[2] Feigenbaum A.V. - Raising the bar [in] Quality Progress, July, 2008, pp. 22-27.

[3] Haverty M., Gorton M. - Integrating market orientation and competitive benchmarking: a methodological framework and application [in] Total Quality Management and Business Excellence, Vol. 17, No. 8, October 2006, pp. 1077-1091.

[4] Hughes S., Karapetrovic S. - ISO 10002 Complaints handling system: a case study [in] International Journal of Quality and Reliability Management, Vol. 23, No. 9, 2006, pp. 1158-1175.

[5] Jang C.C. - Improvement Actions Based on the Customers' Satisfaction Survey. Total Quality Management and Business Excellence, Vol. 14, No. 8, 2006, pp. 919-930.

[6] Juran J.M., Gryna F.M. - Juran's Quality Control Handbook. New York 1951.

[7] Shewhart W. - Economic Control of Manufactured Product. D. Van Nostrand Co., New York, NY 1931. 
[8] Sower V.E., Quarles R., Broussard E. - Cost of quality usage and its relationship to quality system maturity [in] International Journal of Quality \& Reliability Management, Vol. 24, No. 2, 2007, pp. 121-140.

[9] Stimson W., Dlugopolski T. - Financial Control And Quality, Quality Progress, May, 2007, pp. 26-31.

[10] Szczepańska K. - Koszty jakości dla inżynierów. Placet, Warszawa 2009, pp. 265.

[11] Szczepańska K. - Zarzqdzanie jakościq. W dqżeniu do doskonałości. C.H. Beck, Warszawa 2011, pp. 343.
[12] Urbaniak M. - Zarzqdzanie ryzykiem jako wyznacznik doskonalenia produktów i procesów [in] Zarządzanie jakością wybranych procesów. Modelowanie, doskonalenie, metody, bezpieczeństwo, satysfakcja (ed. Żuchowski J.) Wydawnictwo Politechniki Radomskiej, 2010, pp. 157-170.

[13] Vos J.F.J., Huitema G.B. - How organisations can learn from Complaints [in] The TQM Journal, Vol. 20, No. 1, 2008, pp. 8-17.

[14] Witt F.J. - Controlling - Ganzheitliches Controlling. Verlag C. H. Beck, München 2000, p. 251.

[15] PN-EN ISO 19011:2003, Polski Komitet Normalizacyjny, Warszawa 2000. 